\title{
El perenne enfrentamiento entre intimidad y conciencia en Rosas Artificiales de Gabriel García Márquez
}

\section{The Perennial Conflict between \\ Conscience and Intimacy in Rosas Artificiales by Gabriel García Márquez}

\section{Oscar Flórez*}

Recibido: 5 de mayo de 2008 • Aprobado: 2 de septiembre de 2008

\section{Resumen}

Este documento es parte de un proyecto de investigación más amplio patrocinado por la Universidad de Canberra sobre el tema general de análisis e interpretación de historias literarias cortas. Uno de los elementos clave en la interpretación de una historia se define en la manera como el autor estructura su argumento. El acercamiento sobre cómo desarrollar el tema del cuento depende en gran medida sobre cómo el escritor estructura la acción de la historia.

Esta forma es el resultado de un proceso de concentración que no permite disipación o extensión y en el cual los elementos

\footnotetext{
* Profesor de la Universidad de Canberra Australia. Correo electrónico: Oscar.Florez@canberra. edu.au.
} 
realmente significativos se están perfeccionando. Debido a este proceso de concentración de tiempo, narrativa y ajuste, el autor logra encapsular sin retrasos o distracciones una acción simple o un acontecimiento cuyo argumento tiene bastante intensidad para ser tomado como una síntesis significativa. Debido a su longitud, un cuento implica una estructura, cuya característica esencial debe ser de forma significativa y autónoma

El escritor de un cuento es limitado por coacciones de género. Él selecciona un acontecimiento que sea suficientemente significativo y que sirva como una ventana, que le permite al lector trascender la anécdota y vislumbrar el tema encapsulado en el argumento. $A$ través de éste, el autor muestra al lector una realidad más amplia; él hace que el lector supere una realidad con un significado más universal como una visión dinámica que va más allá del aspecto anecdótiço del argumento. Como Julio Cortázar expresó: "un cuento es significativo cuando se separa de sus propios límites con una explosión de energía espiritual que de repente hace brillar algo que supera la pequeña y a veces miserable historia que está siendo relatada".

A través del análisis de las diferentes partes que configuran la estructura y la interpretación que el lector posteriormente le da, se llega a la síntesis, al tema de la historia, "anclada" en la trama. Cuanto menos se exprese explícitamente el significado temático en el argumento, más simbólica y alegórica es la interpretación. En este caso el análisis de la estructura narrativa usada por el autor para diseñar el argumento, es esencial para interpretar el tema involucrado en la narrativa.

Rosas artificiales de Gabriel García Márquez es un ejemplo claro de la importancia del análisis de la estructura narrativa en la interpretación del tema en la historia. En esta historia el Nóbel colombiano cuenta el conflicto, que comenzó temprano en la mañana del primer viernes del mes, entre una abuela ciega y su nieta, porque la joven muchacha no podía ir a misa y omitió la Sagrada Comunión. Ella no 
podía asistir a la misa, al parecer, porque no podía usar las mangas desmontables de su vestido que solía usar para ir a la iglesia, porque la abuela las había lavado y aún estaban mojadas.

En este escrito se va a mostrar que este acontecimiento y la manera como García Márquez ha estructurado su argumento son bastante significativos para mostrar al lector un aspecto de la realidad humana: el eterno conflicto entre la conciencia y la intimidad que los seres humanos experimentan en su vida diaria. Esta síntesis significativa es lo que proponemos como el tema de Rosas artificiales

\section{Palabras clave}

Rosas Artificiales, García Márquez, literatura colombiana, intimidad, conciencia.

\section{Abstract}

This paper is part of a wider research project sponsored by the University of Canberra on the general topic of Analysis and Interpretation of literary short stories.

One of the key elements in interpreting a short story is defined in the way the author structures its plot. The approach on how to develop the theme of the short story depends a great deal on how the writer structures the action of the story.

Due to its length, a short story entails a structure whose essential characteristic is to be a meaningful and self-contained form.

This form is the result of a process of concentration which does not allow dissipation or expansion and in which the really meaningful elements are being refined. Due to this concentration process of narrative time and setting, the author manages to encapsulate without delays or diversions a simple action or event whose plot has enough intensity to be captured as a meaningful synthesis. 
The writer of a short story is limited by genre constraints. He selects an event that is sufficiently meaningful and that serves as a window that allows the reader to transcend the anecdote and to glimpse the theme encapsulated in the plot. Through the plot the author shows the reader a wider reality; he makes the reader transcend to a reality with a more universal meaning as a dynamic vision that goes beyond the anecdotal aspect of the plot. As Julio Cortázar put it "a short story is meaningful when it breaks away from its own limits with an explosion of spiritual energy that suddenly brightens something that transcends the small and sometimes miserable story that is being narrated".

One arrives at that synthesis, at the theme of the story, "locked" in the plot, through the analysis of the different parts that configure its structure and the interpretation that the reader subsequently gives to it.

The less explicitly this thematic meaning is expressed in the plot the more symbolic and allegoric the interpretation will be. In this case the analysis of the narrative structure used by the author to design the plot becomes essential for interpreting the theme embedded in the narrative.

Rosas artificiales by Gabriel García Márquez is a clear example of the importance of the analysis of the narrative structure in interpreting the theme in the story. In this story the Colombian Nobel tells of the conflict between a blind grandmother and her granddaughter that started in the early morning of the first Friday of the month because the young girl could not go to mass and missed the Holy Communion. She could not attend mass apparently because she could not wear the detachable sleeves of her dress which she needed to go to church, because the grandmother had washed them and they were still wet.

We will show in this paper that this event and the way Garcia Márquez has structured its plot are meaningful enough to show the reader an aspect of human reality: the perennial conflict between 
conscience and intimacy that human beings experience in their everyday life. This meaningful synthesis is what we propose as the theme of Rosas artificiales.

\section{Key words}

Rosas Artificiales, García Márquez, colombian literature intimacy conscience.

Uno de los elementos clave en la interpretación de un cuento es la manera como el autor configura el argumento. De la forma como el escritor estructura la trama depende, en gran parte, el enfoque que le da al desarrollo del tema que quiere tratar con la historia narrada. Por su brevedad, el cuento exige una estructura cuya característica esencial es la de ser una forma "cerrada y significativa", resultado de un proceso de concentración en el que no hay ni disgregaciones ni amplificaciones y en el que se depuran los elementos realmente significativos. Gracias a este proceso de concentración del tiempo y del espacio narrativo, el autor logra encerrar en un cuento, sin dilaciones ni preámbulos, un evento o un acontecimiento, cuya trama posee suficiente intensidad como para ser captada como una síntesis significativa. Cortázar afirmaba que "un cuento es significativo cuando quiebra sus propios límites con esa explosión de energía espiritual que ilumina bruscamente algo que va más allá de la pequeña y a veces miserable anécdota que cuenta"1 (Cortázar, 1997, p. 385).

\footnotetext{
1 Cortázar afirmaba que "el fotógrafo o el cuentista se ven precisados a escoger y limitar una imagen o un acontecimiento que sean significativos, que no solamente valgan por si mismos, sino que sean capaces de actuar en el espectador o en el lector como una especie de apertura, de fermento que proyecta la inteligencia y la sensibilidad hacia algo que va mucho más allá de la anécdota visual o literaria contenidas en la foto o en el cuento" (Cortázar, 1997, p. 385).
} 
A esta síntesis significativa que está "encerrada" en la historia contada, calificada normalmente como "el tema" del cuento ${ }^{2}$ se llega a través del análisis de los elementos que configuran la historia, en particular, de su estructura y de la consecuente interpretación que se le da a ella. Entre menos explicito se presente este significado temático en lo narrado, su interpretación será más simbólica y alegórica, y el análisis de la estructura narrativa con la que el autor armó la historia, se hace esencial para llegar a la interpretación del tema tratado.

Rosas artificiales, de Gabriel García Márquez, ejemplifica con claridad las afirmaciones que se acaban de hacer. Parafraseando a Julio Cortázar, el Nobel colombiano ha escogido en Rosas artificiales "un acontecimiento real o ficticio, un vulgar episodio doméstico"(Cortazar, 1997, p. 386); el enfrentamiento que se dio un primer viernes entre una nieta y su abuela ciega, debido a que la joven no pudo ir a misa supuestamente porque la abuela le había lavado las mangas postizas. Este episodio posee, como se verá a lo largo del artículo, esa misteriosa propiedad de irradiar algo más allá de sí mismo, al punto que, se convierte en un resumen implacable de un aspecto de la realidad humana. Es esta síntesis significativa la que se va proponer como el verdadero tema de Rosas artificiales.

La historia está dividida claramente en dos partes, las cuales se van a proponer como la estructura narrativa de este relato. El autor muestra intencionalmente esta división al final de cada parte, con la entrada en escena de la madre de Mina, y las dos afirmaciones que hace la abuela ciega de que "se está volviendo loca" (García Márquez, 1988), en la primera parte, y que "está loca", en la segunda. Este análisis de la estructura servirá como guía y soporte para la interpretación del cuento.

$2 \quad$ En palabras de Cortázar "el elemento significativo de un cuento pareceria residir principalmente en su tema, en el hecho de escoger un acontecimiento real o ficticio que posea esa misteriosa propiedad de irradiar algo más allá de si mismo, al punto que un vulgar epişodio doméstico, como ocurre en tantos admirables relatos de Katherine Mansfield o de un Shenwood Anderson, se convierta en un resumen implacable de una cierta condición humana, o en el símbolo quemante de un orden social o histórico" (1997, p. 386). 
En la madrugada de un primer viernes, Mina, una joven de un pueblo, siguiendo la tradición católica, sale de casa con la supuesta intención de ir a misa y comulgar, después de haber tenido una discusión con su abuela, debido a que las mangas postizas de su vestido, que necesita para ir a misa, estaban todavía húmedas. La abuela, quien es ciega, las había lavado la noche anterior, sin haberle dicho nada a la nieta y no recordado que el dia siguiente era primer viernes. Después de un cuarto de hora, Mina regresa a casa de mal humor y, mientras va al excusado, le dice a la abuela con resentimiento que no puede ir a misa, porque las mangas están mojadas y toda su ropa está sin planchar. Al volver del excusado, la abuela le recuerda que es primer viernes y que debería ir a misa. La nieta, mientras se dirige a su cuarto, y aún más enojada y llorando de rabia, le hecha la culpa a la ciega de haberle hecho perder la comunión. La ciega, al recoger del suelo la taza que había dejado la nieta con el café aún sin probar, murmura que "Dios sabe que ella tiene la conciencia tranquila". En ese momento entra la madre de Mina y a la pregunta de que con quién hablaba, la ciega le responde: "Con nadie [...] Ya te he dicho que me estoy volviendo loca" (García Márquez, 1988).

García Márquez, al mostrarnos el conflicto que se da entre una abuela ciega y su nieta y la influencia de una norma religiosa en la gente del pueblo, comienza a desarrollar el tema definiendo, en primer lugar, a los protagonistas temáticos y el tipo de relación que se da entre ellos. El autor usa esta primera parte del relato para darnos las primeras piezas interpretativas del tema, al que estamos teniendo acceso solamente a partir de lo narrado en el texto y que, claramente, trasciende la anécdota narrada.

El primer elemento estructural que salta a la vista como significativo es el hecho de que abuela y nieta duermen en la misma pieza y de que, desde el principio, se da un enfrentamiento entre ellas, debido a que la nieta no piensa ir a misa y comulgar el primer viernes; de esta forma, no cumple con una norma religiosa en la tradición católica. Además de la característica de que la abuela no puede ver, García Márquez explícita el papel de "supervisor", de "fuente de reflexión", de la abuela ciega sobre lo que hace la nieta en relación con el código moral determinado por una tradición religiosa, en este caso la 
católica. Este papel de "supervisora" se ve confrontado y cuestionado por la nieta, al querer responsabilizar a la abuela de no poder ir a misa, puesto que fue ella quien lavó las mangas postizas que la nieta necesita para ir a misa y poder comulgar, ya que "El padre Ángel no le daría la comunión con un vestido de hombros descubiertos" (García Márquez, 1988). Este evento origina el enfrentamiento entre la nieta y la abuela ciega y se expresa claramente con el pedido imperativo de la nieta de "No vuelvas a coger mis cosas". Este enfrentamiento, que va a ser una constante a lo largo del cuento, define la relación entre la nieta y la abuela ciega, los dos protagonistas temáticos.

Se hace más obvio y explícito este papel de "supervisora" de la ciega, cuando detecta el enojo de la nieta antes de salir de casa y le recuerda que es un "sacrilegio comulgar cuando se tiene rabia". El narrador lo define alegóricamente como "mirada clarividente", cuando comenta que Mina "se sintió perseguida por una mirada clarividente", al volver de la calle un poco después de haber salido.

El enfrentamiento entre abuela y nieta es claramente la manifestación de un conflicto moral; debido a la acusación implícita que le hace la abuela a la nieta de que estaba "mal" no ir a misa en un primer viernes. El conflicto surge cuando Mina no acepta ninguna responsabilidad por el hecho de no poder ir a misa, después de recibir la desaprobación de la abuela: Mina le dice a la abuela, "con un rencor sordo y sintiendo que se ahogaba en lágrimas" (García Márquez, 1988), que la abuela tenía la culpa y no ella, de no poder ir a misa. Según Mina, la abuela era la responsable de todo por el hecho de haber lavado las mangas la noche anterior. Con rabia, le dice también que "tiene que confesarse", porque le hizo perder la comunión del primer viernes.

Con base en el texto y guiados por la forma como el autor organizó el desarrollo de la trama en esta primera parte, se puede llegar sin dificultad a una interpretación, en la que la abuela representa la conciencia, ya que ella, aun siendo ciega, supervisa constantemente a la nieta, hace que ella recuerde sus obligaciones y juzga sus acciones. La ciega "sabe", como una mirada clarividente, lo que pasa con la nieta y juzga lo que ésta hace. Esto da origen al enfrentamiento entre la nieta y la abuela, entre el individuo y su conciencia, 
cuando ésta lo confronta con sus acciones. La abuela es claramente un símbolo de la conciencia.

En esta primera parte García Márquez define en forma alegórica al primero de los dos protagonistas temáticos: la existencia ineludible de la conciencia y su papel de supervisor y juez. Alegoría que es reiterada al final de esta parte, cuando el autor hace alusión a la conciencia como "la loca de casa"' dicho popularmente esparcido en el mundo hispano, y probablemente basado, como extrapolación alegórica, en la conocida metáfora de Santa Teresa de Jesús cuando se refería a la imaginación como la "loca de casa".

El significado temático de la nieta, el otro protagonista a nivel de trama, va a ser definido al comienzo de la segunda parte del cuento. Este personaje ha sido presentado hasta ahora, como alguien que no se puede separar de la abuela y que está íntimamente relacionado con ella, no sólo porque duermen en la misma habitación, sino también porque se siente perseguida a toda hora por la "mirada clarividente" de la abuela ciega.

La segunda parte del cuento comienza con lo que hizo Mina en su cuarto, después del enfrentamiento que tiene con la abuela al regresar de la calle. Encerrada en él, saca un paquete de cartas de un baulito que tenía con llave, de una gaveta del armario que también mantenía bajo llave. Después de cerrar nuevamente con llave el baulito y la gaveta, echa las cartas en el fondo del excusado. Este párrafo define claramente el papel temático de Mina. Ella representa la intimidad que todo individuo guarda "bajo llave", en secreto, y a la cual solamente tiene acceso su propio dueño.

A continuación, con la conversación que sostienen la madre de Mina y la abuela y tangencialmente Mina, García Márquez muestra la unidad esencial de los dos protagonistas temáticos, de la intimidad y la conciencia, como dos aspectos de una misma realidad: la individualidad del ser humano. A la alusión de la madre de que ella pensaba que Mina estaba en misa, no es Mina, sino la abuela, su conciencia a nivel temático, quien en un acto de complicidad tácita con la nieta, responde por ella y da la excusa superficial y aparente 
de que no pudo ir a misa por las mangas mojadas y, además, añade que "ha tenido que trabajar mucho en estos días".

Esta relación de complicidad y mutuo reconocimiento que el narrador nos presenta entre la abuela y la nieta, al ser cuestionada esta última por la madre, se puede válidamente interpretar a nivel de tema, como la misma relación que existe entre intimidad y conciencia. García Márquez se ha valido de la relación que existe entre abuela y nieta, para mostrar alegóricamente la indisoluble relación de complicidad y de reconocimiento que se da entre intimidad y conciencia, dos elementos inseparables que, como dos caras de una moneda, definen al ser humano como un individuo. El reconocimiento recíproco por parte de la abuela y la nieta, la una no existe sin la otra, de que la abuela "sabe", a pesar de ser ciega, a nivel de argumento, lo que realmente le pasa a Mina, se puede interpretar temáticamente como el reconocimiento alegórico de que la conciencia del individuo"sabe" siempre todo lo que pasa en su intimidad.

Al ser llamado a responder por sus acciones, el individuo; o mejor, la individualidad compuesta por la intimidad (Mina) y su conciencia (la abuela ciega), deja que la conciencia (la abuela) reaccione y responda por la acción cuestionada. Esta propuesta la desarrolla y sustenta el autor en las dos escenas finales que completan la segunda parte de la estructura narrativa: la visita de Trinidad, una solterona amiga y compañera de trabajo de Mina y la confrontación final entre abuela y nieta, que es interrumpida por la llegada de la madre; interrupción que -como se dijo antes- sirve de recurso estructural para marcar el final de la segunda parte, al igual que lo hiciera en la primera.

La escena siguiente tiene lugar en la sala de la casa, a donde llega Trinidad con una caja debajo del brazo, para ayudarle a Mina a hacer rosas artificiales para la iglesia. Siendo interrogada por su amiga de por qué no había ido a misa, Mina le da la misma excusa de las mangas mojadas. Ante la opinión de Trinidad de que ésa no era una excusa válida, pues cualquiera le hubiera podido prestar las mangas, Mina admite que fue porque se le hizo tarde. Mientras trabajan, Mina se entera de que lo que hay en la caja son ratones muertos. En el breve diálogo que sigue, después de haber hecho sentir in- 
cómoda a Trinidad por los zapatos de hombre que llevaba puestos, Mina le cuenta en tono confidencial que la verdadera razón de no haber ido a misa fue porque su novio se había ido y que su relación había terminado.

García Márquez, con esta escena, añade temáticamente que a la intimidad, sólo tienen acceso sus dueños y que si otras personas acceden a ella, es porque el individuo se lo permite, "liberándose" de su peso. Hasta este momento, solamente Mina y ahora Trinidad saben la verdadera causa de por qué Mina perdió la misa y la comunión. Sin embargo, el autor va a mostrar en la última escena que hay alguien más que lo sabe: la abuela, a nivel de trama; es decir, la conciencia de Mina a nivel de tema, con quien, quiéralo o no, tiene que enfrentarse y de quien no puede desprenderse. La abuela ciega está siempre atenta a lo que pasa con la nieta, la sigue a todas partes como en la primera parte de la narración y, cuando no está con ella físicamente, deduce por raciocinio y por asociación lo que pasa con la nieta. Simbólicamente, sucede lo mismo con la conciencia; la ciega que lo "sabe" todo y que nos sigue a todas partes, nos cuestiona y nos hace ver la verdad de nuestra intimidad aunque no queramos admitirla.

Antes de echar por el excusado los ratones que trajo Trinidad, Mina confronta a la abuela con el reto de que adivine qué es lo que hay en la caja de cartón. Después de hacerla sonar tres veces, la ciega no puede adivinar, por lo que Mina le confiesa que son los ratones muertos que habían caido la noche anterior en las trampas de la iglesia.

El autor se vale de esta prueba para confirmar temáticamente la indisoluble unidad entre intimidad y conciencia. La abuela sólo tiene acceso a lo que pasa con Mina, a su intimidad, y no puede "saber" lo que pasa con Trinidad, ya que la conciencia sólo tiene acceso a la intimidad que le pertenece y con la cual forman la individualidad de un ser humano. Trinidad con sus zapatos masculinos es una solterona que se dedica a servirle a la iglesia, una chica sin esperanzas de casarse, cuyas ilusiones y sueños están muertos, simbólicamente como los ratones que ella recogió en la iglesia. La abuela, la conciencia de la intimidad de Mina, no pudo "saber" lo que hay en la caja, porque, temáticamente, en ella está la intimidad de Trinidad, sus sueños e 
ilusiones muertas, intimidad que tiene su propia "abuela ciega", es decir, su propia conciencia. Sin embargo, la abuela ciega de Mina sabe perfectamente todo lo que pasa con ella, así como nuestra conciencia "sabe" todo lo que pasa en nuestra intimidad, depositaria de nuestros sueños e ilusiones. La última escena, precisamente, hace explícito, este"saber omnipresente" de la abuela sobre Mina, interpretado temáticamente como el "saber omnipresente" de la conciencia sobre la intimidad.

Esta escena, compuesta por el diálogo final entre abuela y nieta, comienza cuando la nieta regresa del excusado y es perseguida por la abuela, quien le aconseja que si quiere ser feliz "es mejor que no se confiese con extraños", haciendo alusión a la confidencia que Mina le hizo a Trinidad mientras trabajaban. La ciega, después de decirle que ella sabe que está nerviosa, le hace caer en cuenta que la razón por la que no fue a misa no fueron las mangas mojadas, sino el encuentro que tuvo, camino a la iglesia, con "alguien que la esperaba y que le ocasionó una contrariedad". Sorprendida de que la abuela lo sepa todo, Mina pasa "la mano enfrente a los ojos de la abuela, como limpiando un cristal invisible" y le dice: "Eres adivina". La abuela, después de recordarle que ha ido al excusado dos veces, siendo que normalmente va sólo una, le pregunta que si "sería capaz de mostrarle lo que guarda en la gaveta del armario". La nieta, entregándole las llaves que guarda en el corpiño, le responde que vaya "a verlo con sus propios ojos". La ciega, al responderle que "Mis ojos no pueden ver en el fondo del excusado", le da a conocer a Mina que ella, no solamente sabe que la nieta tenía algo guardado celosamente en el armario, sino que también sabe que eso que guardaba lo había tirado ya por el excusado. Mina, aún más sorprendida con lo que sabe la abuela, le sugiere que se tire al fondo del excusado si es que le interesan tanto sus cosas.

A continuación, la abuela le da a conocer a Mina que ella "sabe" también que lo que botó en el excusado eran las cartas que Mina escribía en la cama hasta la madrugada a la luz de una linterna de mano. Por su respiración sabía que eran cartas de amor, que no tendrían nada de particular, si no fuera que dichas cartas fueron la verdadera causa de que Mina hubiera perdido la comunión del primer viernes. La abuela, a pesar de ser ciega, está completamente en- 
terada de lo que pasa con la nieta, no sólo en su comportamiento exterior, sino también de lo que pasa en el interior de ella.

Mina, como último esfuerzo para esconder la verdad; o mejor, para no aceptar como cierto lo que la abuela le decía, la encara y le pregunta: “QQuieres entonces que te diga que fui a hacer al excusado?". Sin darle tiempo a la abuela para contestar, ella misma se responde: "Fui a cagar", respuesta que expresa su reacción a la fastidiosa, aunque reveladora e inevitable, intromisión de la abuela. Como dijimos antes, el autor termina esta segunda parte con el mismo recurso narrativo: la llegada de la madre de Mina y la afirmación de la ciega de que "está loca, pero que por lo visto no piensan mandarla al manicomio mientras no empiece a tirar piedras"; de esta forma, reitera el significado alegórico de la conciencia como "la loca de casa".

Toda esta última escena, a nivel de tema, es obviamente una descripción alegórica de la lucha interna que libran la intimidad con su propia conciencia para llegar al fondo de las cosas. En el ser humano, al ser obligado por su conciencia a reflexionar sobre sus acciones, se da siempre un enfrentamiento entre intimidad y conciencia, a fin de que el individuo admita la verdad y acepte la responsabilidad moral de sus actos. En este perenne conflicto, y que es precisamente lo que García Márquez propone con esta historia, gústele o no a la intimidad del ser humano, siempre sale triunfante la conciencia, ya que, como la abuela, siempre tendrá la última palabra y nos obligará a ver la verdad desnuda de nuestras acciones, de nuestra intimidad, aunque busquemos excusas y rehusemos aceptar nuestra responsabilidad hasta el último momento, de la misma forma que Mina trató de hacerlo a lo largo del cuento, en particular, en esta última escena.

Además, García Márquez muestra indirectamente el papel de la religión y el código moral de la iglesia, en este caso la católica, sobre el individuo en la formación de su conciencia; es decir, de su propio código moral. Este autor considera este papel como un determinante esencial en el perenne enfrentamiento entre intimidad y conciencia, puesto que lo que dice la religión y su código moral influye y determina a la conciencia, cuando juzga y acusa a la intimidad si ésta no se rige a lo que está prescrito por ella. En realidad, la 
iglesia y su doctrina, cualquier que sea, determinan y guían las conciencias individuales de sus miembros cuando éstos juzgan la moralidad de sus acciones. Lo esencial para la abuela, para la conciencia de la intimidad de Mina y que está omnipresente en ella, es recordarle que "es un sacrilegio comulgar cuando se tiene rabia", en la primera parte de la narración; y que haber peleado con su novio no tendría nada de malo si no fuera porque eso "le hizo perder la comunión del primer viernes".

Para concluir, se podría pensar, si miramos solamente lo anecdótico del relato, que lo que García Márquez quiere mostrarnos con este cuento, es que si una persona usa su capacidad de raciocinio y asociación puede llegar a la verdad de los hechos, mensaje que se pude sintetizar perfectamente en el dicho popular "más sabe el diablo por viejo que por diablo". Sin embargo, si nos basamos en el análisis e interpretación que se acaba de proponer, es fácil ver que el autor, con la forma como estructuró el relato, trasciende la anécdota de lo narrado, para revelarnos su peculiar percepción de una de las características universales del ser humano, mirado como una individualidad integrada por una intimidad y su propia conciencia. Un lector atento, al analizar e interpretar lo narrado, razona y asocia al igual que la abuela ciega en el relato, para llegar al "verdadero" tema que García Márquez ha desarrollado en Rosas artificiales: el perenne enfrentamiento entre intimidad y conciencia, entendido como un continuo supervisar, cuestionar y juzgar de esta última sobre la intimidad, para que el individuo no se engañe a si mismo y acepte la responsabilidad moral de sus propios actos.

\section{Referencias}

Cortázar, J. (1997). Algunos aspectos del cuento. En Carlos Pacheco y Luis Barrera Linares (compiladores). Del cuento y sus alrededores ( $2^{\mathrm{a}}$ edición) (pp. 385 ss). Monte Ávila Editores Latinoamericana.

García Márquez, G. (1988). Rosas artificiales. En James H. Hoodie. Vivencias hispánicas. Cuentos del siglo XX. Harcourt Brace Jovanovich. 